\title{
Inhibin and secretion of FSH in oestrous cycles of cows and pigs
}

\author{
K. Taya, H. Kaneko*, G. Watanabe and S. Sasamoto \\ Laboratory of Veterinary Physiology, Tokyo University of Agriculture and Technology, Fuchu, \\ Tokyo 183, Japan; and *Department of Animal Production, Kyushu National Agricultural \\ Experiment Station, Nishigoshi, Kumamoto 861-11, Japan
}

Keywords: inhibin; oestradiol; cow; pig; FSH

\section{Introduction}

Pituitary follicle-stimulating hormone (FSH) is essential for development and maintenance of ovarian follicles in single and multiple ovulating species. The concentrations of FSH in peripheral plasma are maintained by stimulatory effects of gonadotrophin-releasing hormone (GnRH) from the hypothalamus and inhibitory effects of secretions from ovaries, such as steroid hormones and inhibin. Recently, two more ovarian peptides, activin (FSH-releasing protein) (Vale et al., 1986; Ling et al., 1986) and follistatin (FSH-suppressing protein) (Robertson et al,, 1987; Ying et al,, 1987a), have been isolated from pig ( $\mathrm{pFF}$ ) and bovine ( $\mathrm{bFF}$ ) follicular fluids, although the existence of these peptides in the peripheral blood has not yet been demonstrated. In the present review, we summarize the role of inhibin and steroid hormones for the control of FSH secretion in cows and pigs, with discussion using relative findings in rats obtained in our laboratory.

\section{Bioassay of inhibin}

The biological activity of inhibin preparations has been measured by in-vitro bioassays using the rat pituitary cell culture system (de Jong et al., 1979) or sheep pituitary cells (Tsonis et al, 1986). These in-vitro bioassays have been successfully applied to the materials of inhibin-rich tissues, fluids and ovarian vein plasma. In general, however, the sensitivity of these assays is not high enough to measure inhibin concentrations in peripheral blood. Therefore, it has been difficult to examine in detail the physiological role of inhibin. However, a sensitive radioimmunoassay is now available to determine inhibin concentrations in peripheral blood.

\section{Radioimmunoassay (RIA) of inhibin}

A sensitive and convenient radioimmunoassay for inhibin has been developed by using antibodies against pig follicular inhibin (Hasegawa et al., 1988a) and bovine follicular inhibin (McLachlan et al., 1986; Hasegawa et al., 1987; Robertson et al., 1988; Hamada et al., 1989). Radioimmunoassay systems for the measurement of inhibin have also been described using antibodies against a pig inhibin fragment (Bicsak et al., 1986; Rivier et al., 1986; Ying et al., 1987b; Schanbacher, 1988).

Inhibin $\alpha$-subunit monomers, of $M_{\mathrm{r}} 26000$ or 44000 and devoid of biological activity, have been isolated from bovine follicular fluid (Knight et al., 1989; Robertson et al., 1989; Sugino et al., 1989) which was immunoreactive with both antisera against purified bovine inhibin and a synthetic peptide corresponding to the $N$-terminal sequence (1-32) of human inhibin $\alpha$ subunit. Knight et al. (1989) have also demonstrated that inhibin $\alpha$-subunit monomer of $M_{r} 26000$ was found in 
utero-ovarian vein plasma, peripheral plasma and conditioned culture medium from bovine granulosa cells. These results have revealed that the ovary of the cow secretes a monomeric inhibin $\alpha$ subunit. It is therefore quite difficult to obtain accurate concentrations of inhibin in peripheral, ovarian vein blood as well as follicular fluid, when anti-inhibin serum used in the RIA cross-reacted with these monomeric inhibin $\alpha$-subunits. This problem is not resolved at the present time.

\section{Control of FSH secretion in cattle}

\section{Interactions amongst ovarian follicles, inhibin and FSH secretion}

As in most species, after removal of a single ovary in cattle, the remaining ovary compensates and maintains the original ovulatory quota (Johnson et al., 1985). Compensatory ovarian hypertrophy in prepubertal heifers is accompanied by a selective, transient rise in FSH and administration of charcoal-treated bFF prevents both the FSH rise and compensatory ovarian hypertrophy. Treatment of ovariectomized (Ireland et al., 1983; Beard et al., 1988, 1989) and intact (Quirk \& Fortune, 1986) heifers with steroid-free preparations of bFF has been shown specifically to suppress plasma FSH concentrations in a dose-dependent manner, with no significant effect on plasma luteinizing hormone ( $\mathrm{LH}$ ) values. Administration of highly purified bovine inhibin of $M_{\tau} 32000$ to ovariectomized heifers also induced a selective suppression of plasma FSH concentrations in a dosedependent manner without affecting LH levels (Beard et al., 1988). Beard et al. (1989) also provided evidence that bFF inhibits expression of the gene encoding the $\beta$-subunit of FSH. This effect of bFF was apparently specific, since there was no significant effect on pituitary mRNA levels for the common $\alpha$-subunit, LH $\beta$-subunit or thyroid-stimulating hormone $\beta$-subunit. It is likely, therefore, that inhibin regulates FSH production at the pituitary level in cattle by the same mechanism as in sheep (Mercer et al., 1987) and rats (Attardi et al., 1989; Carroll et al., 1989).

On the other hand, biosynthesis of inhibin in granulosa cells is regulated by FSH and LH via a cAMP-mediated pathway in rats (Bicsak et al., 1986; Suzuki et al., 1987), but in man, FSH alone regulates ovarian inhibin (Buckler et al., 1989). It has also been demonstrated that expression of inhibin $\alpha-, \beta_{\mathrm{A}^{-}}$and $\beta_{\mathrm{B}^{\mathrm{B}}}$-subunit mRNAs in rat granulosa cells is under direct control of FSH (Woodruff et al., 1987; Davis et al., 1988; Meunier et al., 1988; Turner et al., 1989). These results indicate that inhibin forms a long-loop endocrine feedback system in which FSH regulates the ovarian production of inhibin, the latter hormone in turn regulating the secretion of FSH, in addition to a classic long-loop endocrine feedback between FSH and ovarian steroid hormones.

\section{Changes in circulating concentrations of inhibin, oestradiol, progesterone, LH and FSH in the normal oestrous cycle of the cow}

There have been few reports describing changes in concentrations of inhibin in peripheral blood during the oestrous cycles of the cow. The profile of serum concentrations of immunoreactive (ir-) inhibin during the normal and stimulated oestrous eycles of the cow was first reported by Hasegawa et al. $(1987,1988 \mathrm{~b})$ using an homologous RIA system.

We have also examined the hormonal profiles in relation to ovarian structure in Japanese brown cows. Figure 1 shows changes in concentrations of ir-inhibin, oestradiol, progesterone, LH and FSH in the plasma during the transition period from the luteal to the follicular phase, the periovulatory period and the early luteal phase in these animals. The pattern of growth and regression of follicles and corpora lutea in the ovary were also characterized by daily ultrasonographic examinations. Concentrations of plasma ir-inhibin of each individual animal are expressed as the percentage of the value at $0 \mathrm{~h}$ (time of $\mathrm{LH}$ peak) to reduce between-animal variations.

The dominant follicle developed in the follicular phase was the ovulatory follicle and another dominant follicle developed in the early luteal phase was the non-ovulatory follicle, each corresponding to the third and first dominant follicle in previous reports (Savio et al., 1988; Sirois \& 
Fortune, 1988). Plasma concentrations of oestradiol increased concomitantly with the growth of the dominant follicle during the follicular and the early luteal phases, but a maximum level of oestradiol of the early luteal phase was significantly lower than that of the follicular phase. Concentrations of plasma ir-inhibin showed a pattern similar to that of oestradiol, although the increase during the early luteal phase was not statistically significant due to large variations in individual animals. A difference between the secretory pattern of FSH and $\mathrm{LH}$ was noted during the period studied. The 4-day period preceding the LH and FSH surges (the follicular phase) was characterized by rapidly declining plasma concentrations of progesterone, followed by concurrent increases in $\mathrm{LH}$, ir-inhibin and oestradiol. Circulating values of FSH, on the other hand, decreased during this period. The different pattern of FSH from that of LH after luteolysis in cows suggests that ovarian products, probably inhibin and oestradiol, from developing dominant follicles may suppress FSH secretion from the pituitary gland. These results also indicate that these declining levels of FSH with a small increase in LH during the follicular phase may be sufficient to develop the dominant ovulatory follicle.

In the early luteal phase, the next dominant follicle (non-ovulatory follicle) started to grow within 1 day after ovulation. A moderate but significant increase in plasma concentrations of oestradiol occurred with a non-significant increase in values of plasma ir-inhibin, followed by a gradual increase in concentrations of progesterone from Day I to Day 7. On about Day 7, plasma concentrations of $\mathrm{LH}$ and FSH remained low.

Changes in concentrations of oestradiol and ir-inhibin in plasma during the periovulatory period agreed well with previous reports of changes in oestradiol (Ireland et al., 1984) and bioactive inhibin (Padmanabhan et al, 1984) in utero-ovarian venous blood. The present results together with these previous studies (Ireland et al., 1984; Hasegawa et al., 1987, 1988b) suggest that ovulatory and non-ovulatory dominant follicles secrete oestradiol and immunoreactive and bioactive inhibin into the circulation, while amounts of oestradiol secreted from dominant non-ovulatory follicles are much less when compared with dominant ovulatory follicles. Bovine corpus luteum cells have been shown not to secrete detectable amounts of bioactive inhibin (Henderson \& Franchimont, 1981) and $\alpha$ - and $\beta_{\mathrm{A}}$-inhibin mRNAs are undetectable in mature fully developed corpora lutea of the cycle and pregnancy (Rodgers et al., 1989; Torney et al., 1989).

In the cow, inhibin and oestradiol are thought to act in combination to cause suppression of secretion of FSH as suggested for the ewe (Martin et al., 1988), probably due to the combined inhibitory feedback action on the pituitary gland. Inhibin and oestrogen have been shown to decrease FSH $\beta$ mRNA (Mercer et al,, 1987; Gharib et al., 1987; Phillips et al., 1988; Attardi et al., 1989; Beard et al., 1989; Carroll et al., 1989).

\section{Superovulating cows}

Figure 2 shows changes in concentrations of ir-inhibin, oestradiol, progesterone, LH and FSH in the peripheral plasma in cattle treated with pig FSH (Kaneko et al., 1990). Concentrations of plasma ir-inhibin and oestradiol rose dramatically after injections of pig FSH and high levels of plasma ir-inhibin were maintained for a longer period than oestradiol after the LH and FSH surge. The mean number of ovulations (corpora lutea) after pig FSH treatment was $5 \cdot 5(\mathrm{~N}=4)$ as determined by rectal palpation on Day 7. Changes in plasma concentrations of ir-inhibin and oestradiol were not correlated with those of progesterone in superovulating cattle. Although changes in endogenous FSH during pig FSH injections (from $72 \mathrm{~h}$ to $12 \mathrm{~h}$ before the $\mathrm{LH}$ peak) could not be determined due to the cross-reaction between pig FSH and antiserum to bovine FSH- $\beta$, peaks of the preovulatory FSH surge in the superovulating cattle were significantly suppressed to $70 \cdot 4 \%$ of values in the intact cycle. After treatment with pig FSH high levels of ir-inhibin together with oestradiol may be involved in a partial suppression of the preovulatory surge of FSH in superovulating cattle, as in superovulating rats (Tsukamoto et al., 1986; Sasamoto et al., 1987). The source of ir-inhibin during the early luteal phase in superovulating cattle is not clear. Large numbers of 


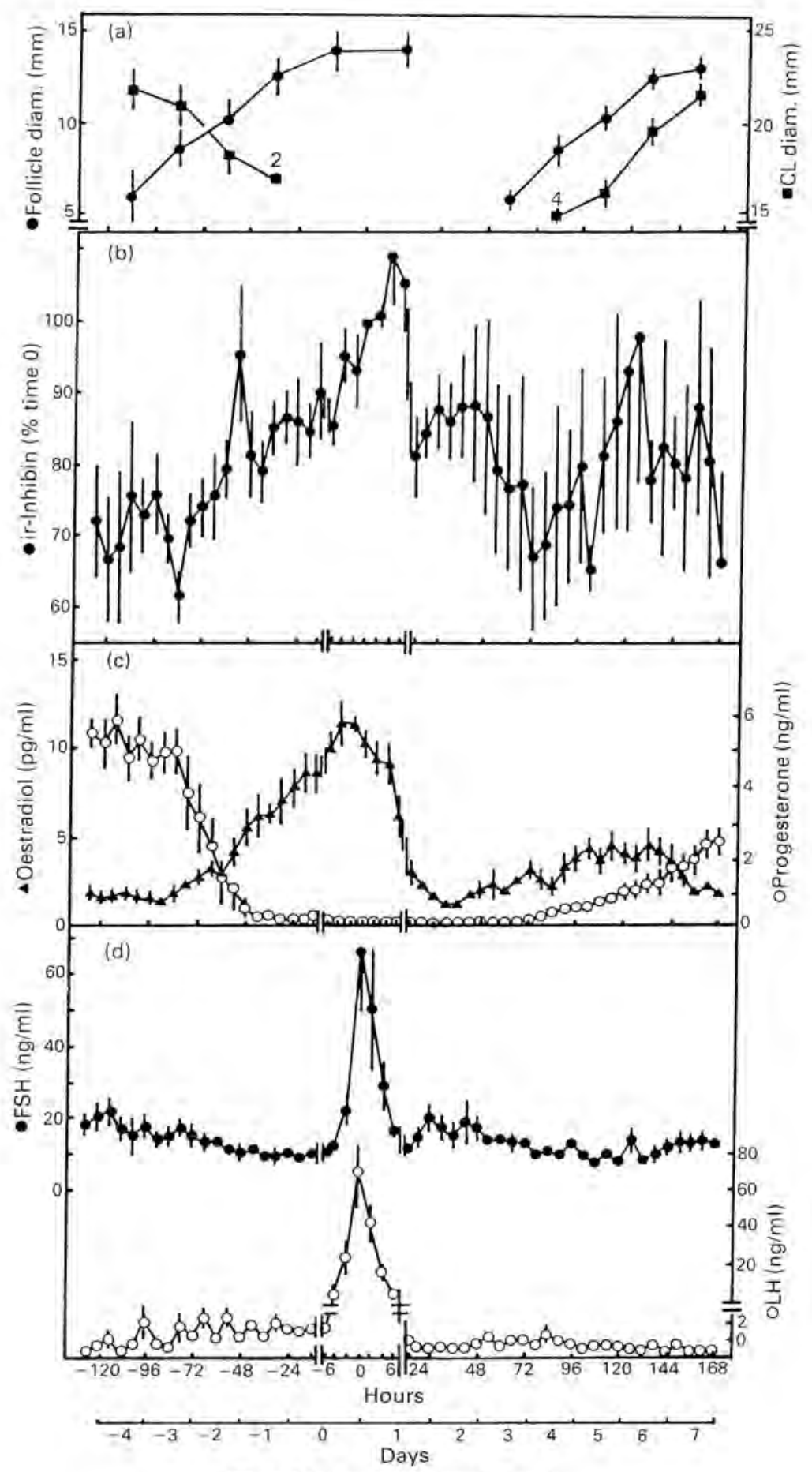

Time from preovulatory $\mathrm{LH}$ peak 
unovulated antral follicles of various sizes were detected after superovulation in FSH-primed cows (Pierson \& Ginther, 1984; Yadav et al., 1986). In addition, granulosa cells from small or atretic follicles have been shown to produce detectable amounts of bioactive inhibin in vitro (Henderson $e t$ al., 1984). Therefore, unovulated follicles may secrete ir-inhibin and be involved in the maintenance of elevated ir-inhibin levels after the LH surge,

Previous reports indicated that the development of ovarian follicles in cattle occurs in waves and that the most common pattern, detected by daily ultrasonographic examination is two (Knopf et al., 1989) or three (Savio et al., 1988; Sirois \& Fortune, 1988) waves during the oestrous cycle, In each wave one follicle was selected to become a morphologically dominant follicle. The results of previous reports (Hasegawa et al., 1987, 1988b; Kaneko et al., 1990) suggest that the ovulatory dominant follicle secretes a large amount of ir-inhibin as well as oestradiol in vivo, whereas nonovulatory dominant follicles secrete only moderate amounts of ir-inhibin and a small amount of oestradiol. It is also suggested that small antral follicles in each of the follicular waves may secrete ir-inhibin but not oestradiol during the oestrous cycle in cows, since granulosa cells of ovarian follicles start secreting bioactive inhibin before these cells have developed a high capacity to secrete oestradiol during the period of follicular maturation (Tsukamoto et al., 1986). They continue to secrete bioactive inhibin for a long time compared to secretion of oestradiol after follicular atresia in the rat (Kaneko et al., 1987),

\section{Problems involved in the present method of inhibin RIA}

The antiserum used in the present and previous studies (Kaneko et al., 1990) cross-reacted with a monomer form of $M_{\mathrm{r}} 26000$ of the $\alpha$-subunit as well as with a form of ir-inhibin of $M_{\mathrm{r}} 32000$, although the former cross-reactivity was much less than that of the latter. Cross-reactivity of the antiserum with a form of $M_{\mathrm{r}} 44000$ was not tested. Although it has been demonstrated that the bovine granulosa cell secretes considerable quantities of monomeric inhibin $\alpha$-subunits (Knight et al., 1989; Robertson et al., 1989; Sugino et al., 1989), there are some contradictory results about the amounts of these $\alpha$-subunits of inhibin. In addition, it has not been demonstrated whether the production of free inhibin $\alpha$-subunits fluctuates during the oestrous cycle and at other reproductive stages. Inhibin bioactivity increases dramatically in peripheral plasma of cows treated with pig FSH to induce superovulation (H. Kaneko, unpublished observations). Therefore, it seems likely that the inhibin radioimmunoassay system used in the present and previous studies (Kaneko el al., 1990) does provide relatively well recognized changes in bioactive inhibin in the peripheral circulation, although at least two forms of bioactive inhibin $\left(M_{\mathrm{r}} 32000\right.$ and 55000$)$ are being measured.

In summary, inhibin and oestradiol are thought to act in combination to cause suppression of secretion of FSH in cyclic cows. During the follicular and early luteal phases, FSH is primarily controlled by synergistic action on the anterior pituitary gland of inhibin and oestradiol from the ovulatory and non-ovulatory dominant follicles. In contrast, inhibin exerts the main suppressive influence on secretion of FSH during the late luteal phase; progesterone may have an additional suppressive effect on the pituitary gland or through a suppressive effect on GnRH pulse frequency. Inhibin may therefore be responsible for tonic suppression of FSH secretion throughout the

Fig. 1. Mean diameters of the dominant follicles (a; ) and corpus luteum (a; $\mathbf{E})$, plasma concentrations of immunoreactive (ir-) inhibin (b; $\bullet$ ), oestradiol $(\mathrm{c} ; \boldsymbol{\Delta})$ ). progesterone (c; $\bigcirc)$, FSH (d: - ) and LH (d; O) during the spontaneous luteal-follicular transition, ovulation and early luteal phase in 5 cows. Results were centred around the LH peak (time 0 ). Values are mean \pm s.e.m. of 5 observations except as indicated. In (b), results of plasma concentrations of ir-inhibin are expressed as \% value of time 0 (at the time of the LH peak in individual animals). (Unpublished observations of H. Kaneko, T. Terada, K. Taya, G. Watanabe, S Sasamoto, Y. Hasegawa \& M. Igarashi.) 


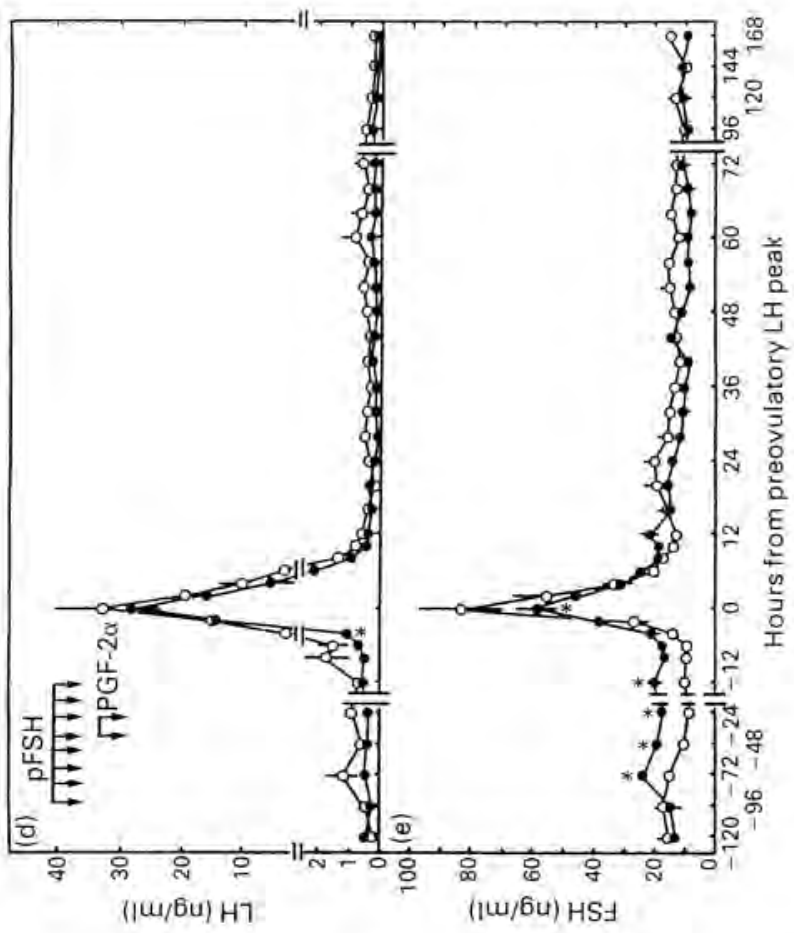

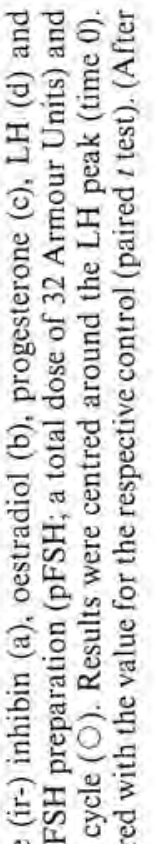

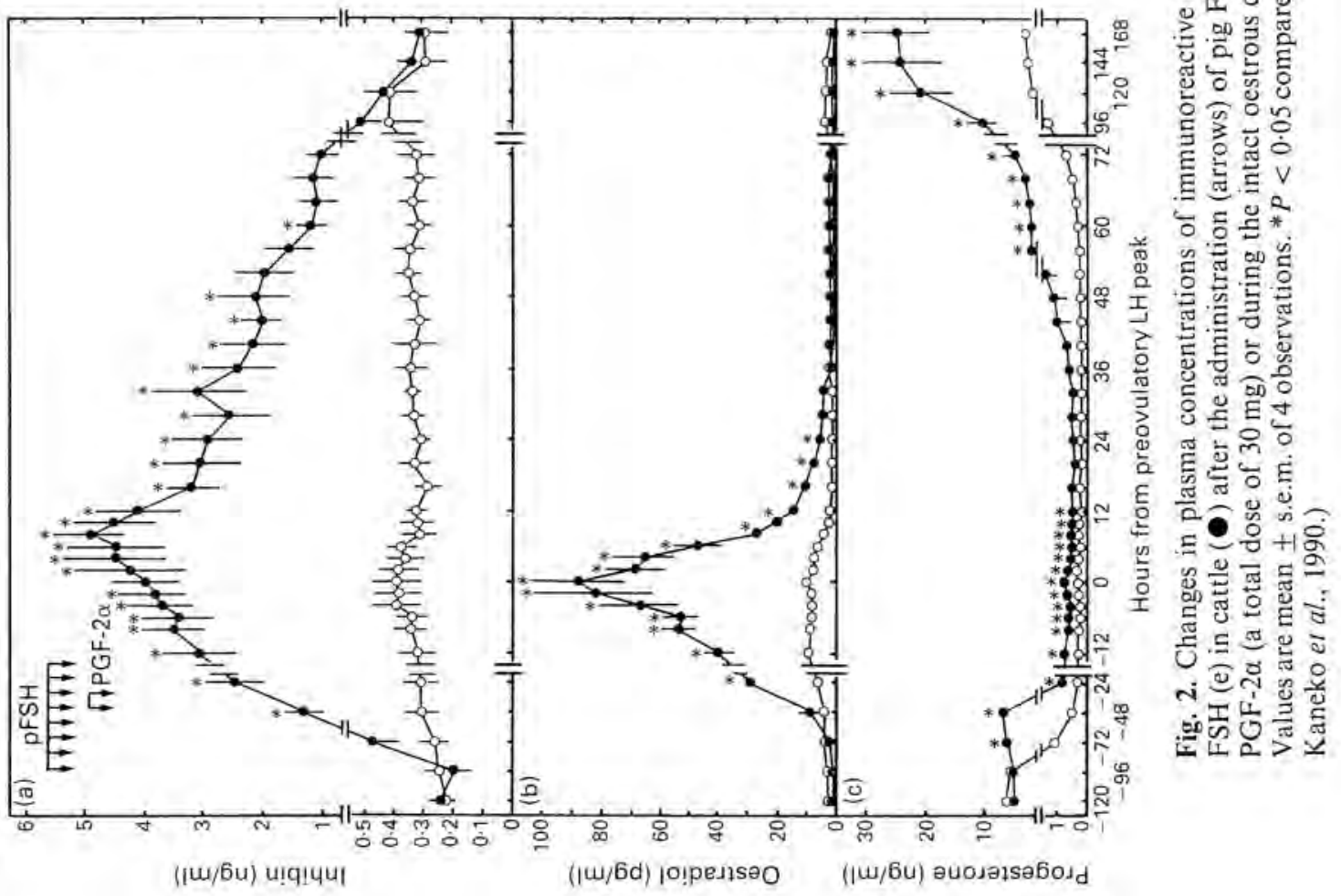




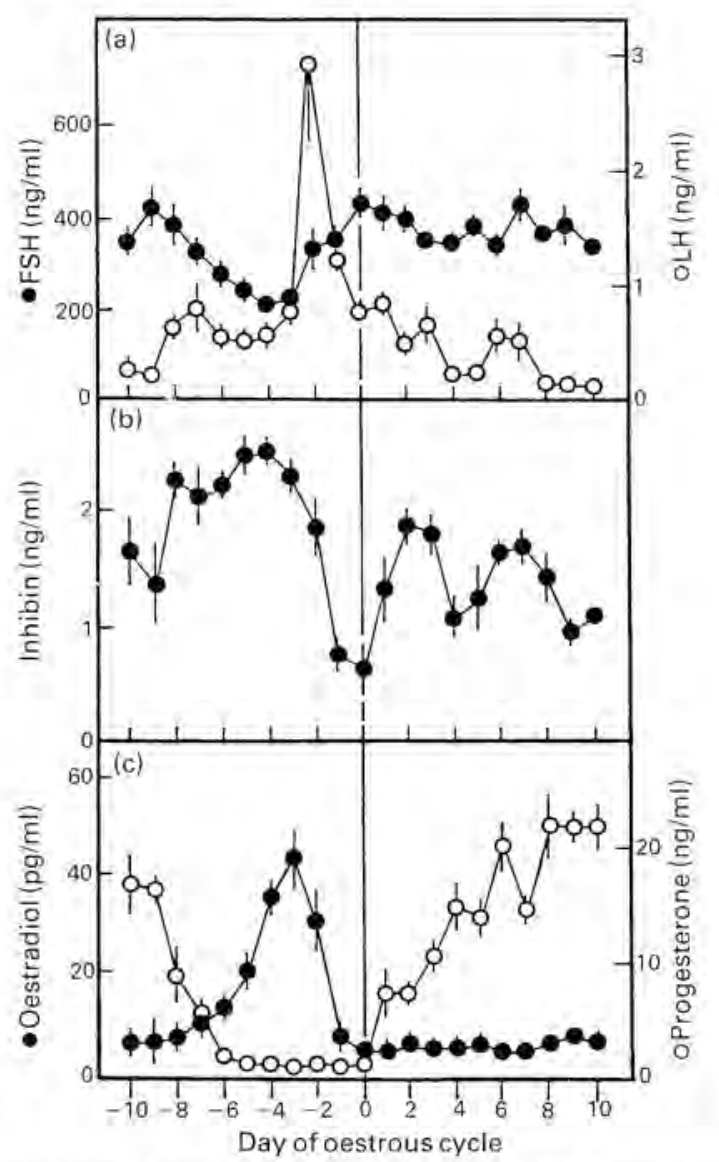

Fig. 3. Mean plasma concentrations of LH (a;O), FSH $(a ;-)$, immunoreactive (ir-) inhibin (b), oestradiol (c; ) and progesterone (c; $O)$ during the oestrous cycle of pigs. Results were centred around the LH peak. Day $0=$ day of ovulation. Values are mean \pm s.e.m. of 5 cycles from 2 pigs. (After Hasegawa et al., 1988a.)

oestrous cycle, while oestradiol may act as an acute suppressor for FSH secretion by synergistic effects with inhibin during the periovulatory period.

\section{Control of FSH secretion in pigs}

\section{Interaction amongst ovarian follicles, inhibin and FSH secretion}

The pig is a typical polytocous animal and the interfollicular relationships in this species differ from those of monotocous animals. The pattern of steroidogenesis in pig follicles is consistent with the two-cell theory of steroidogenesis in that the androgen produced by the theca cells is aromatized to oestrogen by the granulosa cells. The theca cells of this species also produce oestradiol in quantities comparable to those secreted by the granulosa cells. In addition, the dominant follicles in the pig may promote the maturation of the small follicles, in contrast to their inhibitory effect in other species, probably through oestrogens secreted from the dominant follicles (Foxcroft \& Hunter, 1985).

In the pig, as in monotocous or other polytocous species, unilateral ovariectomy is followed by compensatory hypertrophy of the remaining ovary. Unilateral ovariectomy has been shown to 


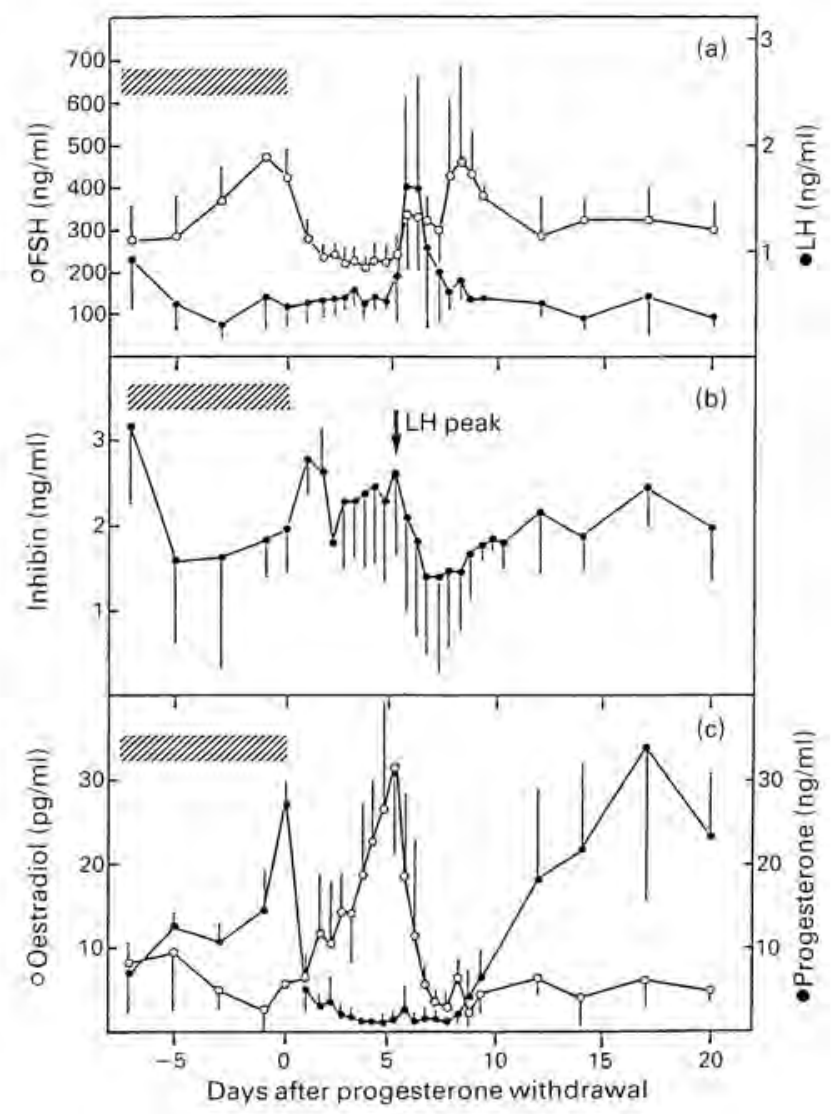

Fig. 4. Changes in mean plasma concentrations of LH (a; - $)$, FSH (a; $\bigcirc)$, immunoreactive (ir-) inhibin (b), oestradiol (c; $O$ ) and progesterone (c; - during and after treatment with progesterone implants in gilts which exhibited oestrus. Progesterone treatment shown as the hatched bar was initiated 14-15 days after the end of the previous oestrus. The day of progesterone withdrawal is designated as Day 0. Results were centred around the LH peak. Values are mean \pm s.e.m. of 4 observations. (After Mukai et al., 1989.)

cause a selective rise in peripheral FSH concentrations (Redmer et al., 1984). Also, concentrations of oestradiol and inhibin bioactivity in ovarian venous plasma greatly increase after unilateral ovariectomy, and then decline as the ovary approaches its final compensated size. Administration of charcoal-treated pig FF during and after unilateral ovariectomy in pigs suppressed the rise in serum FSH concentrations, ovarian hypertrophy and subsequent follicular growth (Redmer et $a I$., 1985,1986 ). Increases in inhibin activity, alone, or in combination with oestradiol, may therefore inhibit sustained elevation of FSH after unilateral ovariectomy. These findings indicate that there is a long-loop endocrine feedback system between FSH and inhibin in pigs,

\section{Changes in circulating concentrations of inhibin, oestradiol, progesterone, LH and FSH}

A sensitive and specific RIA system for pig ovarian inhibin has been developed by Hasegawa et al. (1988a) and they described changes in serum ir-inhibin concentrations during the oestrous cycles of pigs (Fig. 3). Serum concentrations of ir-inhibin gradually increased from the late luteal phase to the early follicular phase. High levels of ir-inhibin during the follicular phase continued for more than 6 days, then concentrations decreased rapidly after the LH surge. Changes in serum concentrations of ir-inhibin were not parallel with those of oestradiol, especially during the luteal phase 
and the early follicular phase when serum concentrations of oestradiol remained quite low. Serum concentrations of FSH were inversely related to those of ir-inhibin rather than to those of oestradiol. Hasegawa et al. (1988a) suggest that the secretion of FSH during the oestrous cycles of pigs is mainly controlled by ovarian inhibin.

Exogenous progesterone delivered from implanted pumps suppressed follicular growth during treatment and prevented the gilts from returning to oestrus. Removal of the progesterone pumps initiated subsequent preovulatory endocrine changes in a normal fashion as shown in Fig. 4 . Progesterone withdrawal initiated an increase in plasma concentrations of ir-inhibin as well as oestradiol and a decrease in plasma concentrations of FSH, although the elevation of ir-inhibin in the plasma preceded the rise of plasma oestradiol. The overall plasma ir-inhibin profiles were inversely correlated with those of FSH. During follicular development, ir-inhibin levels were high while plasma FSH values remained low. After the LH surge, a decline of plasma ir-inhibin preceded the secondary surge of FSH around the time of ovulation. Small follicles, the growth of which had been retarded under the suppressive influence of progesterone, seem to have acquired the ability to secrete ir-inhibin before they started oestradiol secretion, as occurs in rats (Tsukamoto et al, 1986).

These findings suggest that concentrations of ir-inhibin in peripheral plasma vary with the number of healthy follicles and no positive correlation was observed with luteal function during the luteal phase in pigs. Plasma concentrations of ir-inhibin in pigs, as in rats, may be a more direct index of follicular development than oestradiol (Taya et al., 1989).

\section{Follistatin and activin}

Another class of ovarian peptide, follistatin, which is composed of a single polypeptide chain and inhibits the basal secretion of FSH, but not $\mathrm{LH}$, in the rat pituitary cell culture system, has been isolated from pig FF (Ying et al., 1987a) and bovine FF (Robertson et al., 1987). The actions of follistatin have been reported, at least in part, to reduce biosynthesis of FSH at the level of FSH $\beta$ mRNA of the anterior pituitary gland (Carroll et al., 1989), although the inhibiting effect on FSH secretion was far less compared with that of inhibin. Physiological roles of follistatin in the regulation of FSH dynamics remain to be elucidated.

Subunits of inhibin or activin are synthesized within pituitary gonadotrophs and appear to be regulated by gonadal steroids (Roberts et al., 1989). Although a physiological role of pituitary inhibin or activin remains to be specified, systemic administration of recombinant human activin-A to immature female rats (Schwall et al., 1989) or adult male monkeys (McLachlan et al., 1989) can induce a marked increase in serum FSH concentrations without affecting LH values

In addition to action at the pituitary gland, local or autocrine effects of inhibin and activin within the gonads themselves have been reported. Activin has specific receptors in ovarian granulosa cells (Sugino et al., 1988a) and induces expression of FSH receptors (Hasegawa et al., 1988c) and LH receptors in the presence of FSH (Sugino et al., 1988b) on rat granulosa cells. Furthermore, activin was found strongly to enhance the ability of granulosa cells to produce inhibin (Sugino et al., 1988b) and to induce inhibin gene expression (LaPolt et al., 1989), On the other hand, inhibin suppressed granulosa cell aromatase activity (Ying et al., 1986; Hutchinson et al., 1987) and inhibin augmented LH-stimulated androstenedione production by cultured theca cells, while activin was inhibitory.

Gonadal peptides, therefore, may play a role in the control of gonadotrophin action by local regulators at the gonadal level, in addition to the well established inhibitory action of inhibin on pituitary FSH.

This work was supported in part by a grant-in-aid (Bio Media Program) from the Ministry of Agriculture, Forestry and Fisheries (BMP90-II-1-2). 
inhibin during pseudopregnancy, pregnancy and lactation in the rat. J. Endocr. 121, 545-552.

Torney, A.H., Hodgson, Y.M., Forage, R. \& de Kretser, D.M. (1989) Cellular localization of inhibin mRNA in the bovine ovary by in-situ hybridization. $J$. Reprod. Fert. 86, 391-399.

Tsonis, C.G., McNeilly, A.S. \& Baird, D.T. (1986) Measurement of exogenous and endogenous inhibin in sheep serum using a new and extremely sensitive bioassay for inhibin based on inhibition of ovine pituitary FSH secretion in vitro. $J$. Endocr. 110 , $341-352$.

Tsukamoto, I., Taya, K., Watanabe, G. \& Sasamoto, S. (1986) Inhibin activity and secretion of gonadotropin during the period of follicular maturation. Life Sct. 39, $119-125$.

Turner, I.M., Saunders, P.T.K., Shimasaki, S. \& Hillier, S.G. (1989) Regulation of inhibin subunit gene expression by FSH and estradiol in cultured rat granulosa cells. Endocrinoloy 125, 2790-2792.

Vale, W., Rivier, J., Vaughan, J., McClintock, R., Corrigan, A., Woo, W., Karr, D. \& Spiess, J. (1986) Purification and characterization of an FSH releasing protein from porcine ovarian follicular fluid. Nature, Lond. 321, 776-779.
Woodruff, T.K., Meunier, H., Jones, P.B., Hsueh, A.J.W. \& Mayo, K.E. (1987) Rat inhibin: molecular cloning of $\alpha$-and $\beta$-subunit complementary deoxyribonucleic acids and expression in the ovary. Molec. Endocrinol. 1, 561-568.

Yadav, M.C., WaIton, J.S. \& Leslie, K.E. (1986) Timing of the onset and duration of ovulation in superovulated beef heifers. Theriogenology $\mathbf{2 6}$, $509-52 \mathrm{I}$

Ying, S-Y., Becker, A., Ling, N., Ueno, N. \& Guillemin, R. (1986) Inhibin and beta type transforming growth factor (TGF $\beta$ ) have opposite modulating eflects on the follicle stimulating hormone (FSH)-induced aromatase activity of cultured rat granulosa cells. Biochem. Biophys. Res. Commun. 136,969-975.

Ying, S-Y., Becker, A., Swanson, G., Tan, P., Ling, N., Esch, F., Ueno, N., Shimasaki, S. \& Guillemin, R. (1987a) Follistatin specifically inhibits pituitary follicle stimulating hormone release in vitro. Biochem. Biophys. Res. Commun. 149, 133-139.

Ying, S-Y., Czvik, J., Becker, A., Ling, N., Ueno, N. \& Guillemin, R. (1987b) Secretion of folliclestimulating hormone and production of inhibin are reciprocally related. Proc. natn. Acad. Sci. USA 84, $4631-4635$. 